\title{
Fate of rice shoot and root residues, rhizodeposits, and microbe-assimilated carbon in paddy soil - Part 1: Decomposition and priming effect
}

\author{
Zhenke Zhu ${ }^{1,2, *}$, Guanjun Zeng ${ }^{2, *}$, Tida Ge ${ }^{1,2}$, Yajun Hu ${ }^{1}$, Chengli Tong ${ }^{1}$, Olga Shibistova ${ }^{3,4}$, Xinhua He $^{5}$, \\ Juan Wang ${ }^{1}$, Georg Guggenberger ${ }^{1,3}$, and Jinshui Wu ${ }^{1,2}$ \\ ${ }^{1}$ Key Laboratory of Agro-ecological Processes in Subtropical Region, Institute of Subtropical Agriculture, \\ Chinese Academy of Sciences, Hunan, 410125, China \\ ${ }^{2}$ Changsha Research Station for Agricultural and Environmental Monitoring, Institute of Subtropical Agriculture, \\ Chinese Academy of Sciences, Hunan, 410125, China \\ ${ }^{3}$ Institute of Soil Science, Leibniz Universität Hannover, 30419 Hannover, Germany \\ ${ }^{4}$ VN Sukachev Institute of Forest, Siberian Branch, Russian Academy of Science, 660036 Krasnoyarsk, Russian Federation \\ ${ }^{5}$ College of Resources and Environment, Southwest University, Chongqing 400715, China \\ *These authors contributed equally to this work.
}

Correspondence to: Tida Ge (gtd@isa.ac.cn) and Jinshui Wu (jswu@isa.ac.cn)

Received: 12 March 2016 - Published in Biogeosciences Discuss.: 9 May 2016

Revised: 12 July 2016 - Accepted: 12 July 2016 - Published: 11 August 2016

\begin{abstract}
The input of recently photosynthesized $\mathrm{C}$ has significant implications on soil organic $\mathrm{C}$ sequestration, and in paddy soils, both plants and soil microbes contribute to the overall $\mathrm{C}$ input. In the present study, we investigated the fate and priming effect of organic $\mathrm{C}$ from different sources by conducting a 300-day incubation study with four different ${ }^{13} \mathrm{C}$-labelled substrates: rice shoots (shoot-C), rice roots (root-C), rice rhizodeposits (rhizo-C), and microbeassimilated $\mathrm{C}$ (micro-C). The efflux of both ${ }^{13} \mathrm{CO}_{2}$ and ${ }^{13} \mathrm{CH}_{4}$ indicated that the mineralization of $\mathrm{C}$ in shoot-C, root-C-, rhizo-C-, and micro-C-treated soils rapidly increased at the beginning of the incubation and decreased gradually afterwards. The highest cumulative $\mathrm{C}$ mineralization was observed in root-C-treated soil $(45.4 \%)$, followed by shoot-C- (31.9\%), rhizo-C- $(7.90 \%)$, and microC-treated $(7.70 \%)$ soils, which corresponded with mean residence times of 39.5, 50.3, 66.2, and 195 days, respectively. Shoot and root addition increased $\mathrm{C}$ emission from native soil organic carbon (SOC), up to 11.4 and 2.3 times higher than that of the control soil by day 20 , and decreased thereafter. Throughout the incubation period, the priming effect of shoot-C on $\mathrm{CO}_{2}$ and $\mathrm{CH}_{4}$ emission was strongly positive; however, root- $\mathrm{C}$ did not exhibit a significant positive prim-
\end{abstract}

ing effect. Although the total C contents of rhizo-C- $(1.89 \%)$ and micro-C-treated soils $(1.90 \%)$ were higher than those of untreated soil $(1.81 \%)$, no significant differences in cumulative $\mathrm{C}$ emissions were observed. Given that about 0.3 and $0.1 \%$ of the cumulative $\mathrm{C}$ emission were derived from labelled rhizo- $\mathrm{C}$ and micro- $\mathrm{C}$, we concluded that the soil organic C-derived emissions were lower in rhizo-C- and micro$\mathrm{C}$-treated soils than in untreated soil. This indicates that rhizodeposits and microbe-assimilated $\mathrm{C}$ could be used to reduce the mineralization of native SOC and to effectively improve soil $\mathrm{C}$ sequestration. The contrasting behaviour of the different photosynthesized $\mathrm{C}$ substrates suggests that recycling rice roots in paddies is more beneficial than recycling shoots and demonstrates the importance of increasing rhizodeposits and microbe-assimilated $\mathrm{C}$ in paddy soils via nutrient management.

\section{Introduction}

The soils of rice paddies, which cover an area of $\sim 165$ million ha worldwide, hold great potential for expanded $\mathrm{C}$ sequestration (Conrad et al., 2012; Ge et al., 2012; Lal, 2004), 
and the soil organic carbon (SOC) pools in agricultural systems, of which plant $\mathrm{C}$ is the primary substrate, are significantly affected by the input of crop residues (Weintraub et al., 2007). For example, after crops are harvested or die, aboveground biomass, such as straw, stubble, and other surface debris, contribute to annual $\mathrm{C}$ inputs ( $\mathrm{Lu}$ et al., 2003), and photosynthesized $\mathrm{C}$ substrates are continuously released by rice plants as rhizodeposits throughout the growing season (Lu et al., 2002, 2003). Furthermore, autotrophic soil microbes that assimilate $\mathrm{CO}_{2}$ contribute to $\mathrm{C}$ sequestration in paddy soil (Ge et al., 2013; Yuan et al., 2012a), and since $\mathrm{C}$ inputs promote microbial activity and native SOC decomposition (Ye et al., 2015), their quantity and quality influence microbe-mediated decomposition processes (Brant et al., 2006; Creamer et al., 2015). Therefore, the quantification of different $\mathrm{C}$ substrates deposited in paddy soils and their respective effects on native SOC require further investigation.

The aboveground biomass and root systems of rice plants represent one of the most important inputs of available organic C to paddy SOC (Johnson et al., 2006), the quantity and quality of which has been reported previously (Chen et al., 2014; Kisselle et al., 2001; Zhang et al., 2015). However, although aboveground biomass contributes significantly to SOC sequestration (Lu et al., 2003), rice roots have been reported to contribute from 1.5- to 3-fold more $\mathrm{C}$ to $\mathrm{SOC}$ than shoots (Hooker et al., 2005). Similarly, Molina et al. (2001) emphasized that the stalks and leaves of corn contribute $50 \%$ less $\mathrm{C}$ to SOC than the roots and rhizodeposits. The predominant contribution of crop roots to SOC can partly be explained by the chemical composition of roots, which includes cellulose and lignin, as well as by residue-soil interactions, such as aggregate formation, which physically protect organic C from biodegradation (Baumann et al., 2009; Johnson et al., 2006; Lu et al., 2003).

Previous studies have also reported that the rhizodeposits of rice account for $\sim 17 \%$ of the photoassimilates (Nguyen, 2003) that enter paddy soil and that rice rhizodeposits include soluble exudates, root border cells, dead debris, and insoluble mucilage (Lu et al., 2003). In cereal crops, $10-25 \%$ of root exudates are incorporated into SOC, and rhizodeposits are thought to play a key role in $\mathrm{C}$ cycling and sequestration in plant-soil-microbe systems (Kuzyakov et al., 2002, 2003). In addition to the photosynthesized $\mathrm{C}$ substrates of plants, soil microbes are also able to assimilate $\mathrm{CO}_{2}$ via the CalvinBenson-Bassham cycle, thus can significantly contribute to the net uptake and assimilation of atmospheric $\mathrm{CO}_{2}$ as well (Ge et al., 2013; Yuan et al., 2012b). In fact, $\mathrm{CO}_{2}$ uptake by phototrophic soil microbes has been reported to account for up to $0.36 \%$ of the total $\mathrm{C}$ fixed in rice paddy soils and $0.19 \%$ of the total C fixed in upland soils (Ge et al., 2013; Yuan et al., 2012b).

So far, the effect of $\mathrm{C}$ input from different $\mathrm{C}$ sources on the balance and stability of SOC has received limited attention. For example, the $\mathrm{C}$ in roots and shoots occurs as particulate matter and must be first depolymerized before be- ing taken up by microorganisms, whereas rhizodeposits are immediately available for uptake and assimilation by microorganisms, which is an important step in the formation of stable organic matter (Kuzyakov et al., 2002, 2003). As low molecular weight substances, rhizodeposits are also protected from mineralization via adsorption onto soil particles (Jones and Edwards, 1998; Saidy et al., 2012; Sodano et al., 2016), which contributes to the stability and sequestration of SOC (Ge et al., 2012). In addition, different $C$ substrates can also have stimulating or restraining effects on the mineralization of native SOC, which are known as positive or negative priming effects (PEs), respectively (Kuzyakov, 2010). Priming is often caused by the addition of substrates with relatively high $\mathrm{C}$ availability and nutrient contents, which results in increased microbial activity (Blagodatsky et al., 2010; Huo et al., 2013). Hence, such easily degraded compounds greatly enhance the decomposition of native SOC (Blagodatsky et al., 2007; Qiao et al., 2014), compared with the effects of ryegrass, cellulose, or wheat straw, which have complex structures that are less available to microbes (Kuzyakov and Bol, 2006; Kuzyakov et al., 2000). However, since easily available low molecular weight substrates, such as rhizodeposits, can be easily immobilized by microbial metabolism (Lu et al., 2002; Gunina et al., 2014) or adsorption (Jones and Edwards, 1998; Saidy et al., 2012; Sodano et al., 2016), their $\mathrm{PE}$ can be small or even negative (Ge et al., 2012).

Accordingly, the quantity and quality of different $\mathrm{C}$ inputs, as well as their fate and PE in paddy soils, are globally important (Bastida et al., 2013; Johnson et al., 2006; Wang et al., 2015). However, few studies have investigated the fate of plant residues and rhizodeposits in paddy soils, and to the best of our knowledge, there is no comparative information on the decomposition of different organic $\mathrm{C}$ sources, such as rice shoots and roots, rhizodeposits, and microbeassimilated $\mathrm{C}$ or on the effects of different organic $\mathrm{C}$ sources on the mineralization of native SOC. Therefore, the aim of the present study was to investigate the fate and priming effect of organic $\mathrm{C}$ from different sources. We hypothesized that both the decomposition of organic $\mathrm{C}$ sources and their $\mathrm{PE}$ on the decomposition of native soil organic matter would vary, depending on the type of organic $\mathrm{C}$. We assumed that, since shoots and roots enter the soil as unprotected particulate organic residues, both substrates are readily available for microorganisms and that, as a result, such residues should also stimulate the decomposition of native organic matter, whereas rhizodeposits and microbial $\mathrm{C}$ represent more stable $\mathrm{C}$ sources that contribute less to priming. We investigated these hypotheses by quantifying the contribution of different organic $\mathrm{C}$ sources to $\mathrm{CO}_{2}$ and $\mathrm{CH}_{4}$ emissions and by analysing their PEs during a 300-day incubation study, using ${ }^{13} \mathrm{C}$-labelled rice plant residues, rhizodeposits, and microbeassimilated $\mathrm{C}$ in paddy soils. 


\section{Materials and methods}

\subsection{Study site and soil sampling}

The experimental rice field was located at the Changsha Research Station for Agricultural and Environmental Monitoring, Hunan, China $\left(113^{\circ} 19^{\prime} 52 \mathrm{E}, 28^{\circ} 33^{\prime} 04 \mathrm{~N} ; 80 \mathrm{~m}\right.$ above sea level), where the climate is subtropical, with a mean annual temperature and rainfall of $17.5^{\circ} \mathrm{C}$ and $1300 \mathrm{~mm}$, respectively. The soil developed from highly weathered granite and is classified as a typical Stagnic Anthrosol. Moist soil samples were collected from the plough layer $(0-20 \mathrm{~cm})$ and sieved $(<4 \mathrm{~mm})$ to remove visible plant residues. The soil contained $18.1 \mathrm{~g} \mathrm{~kg}^{-1}$ organic $\mathrm{C}$ with a $\delta^{13} \mathrm{C}$ value of $-26.7 \%$ o, $1.8 \mathrm{~g} \mathrm{~kg}^{-1}$ total $\mathrm{N}$, and $0.4 \mathrm{~g} \mathrm{~kg}^{-1}$ total $\mathrm{K}$ and had a $\mathrm{pH}$ of 5.6 at a soil : water ratio $(w / v)$ of $1: 2.5$.

\subsection{Production of ${ }^{13} \mathrm{C}$-labelled substrates}

Rice cultivation and ${ }^{13} \mathrm{CO}_{2}$ labelling were performed as described by Ge et al. (2012, 2013), with some modifications. Briefly, 60 pots were filled with $1 \mathrm{~kg}$ dry soil, and of these, 40 pots were planted with three 30 -day-old rice seedlings (Oryza sativa L. "Zhongzao 39") each, whereas the remaining 20 pots were unplanted.

For ${ }^{13} \mathrm{C}$ labelling, 20 planted and 10 unplanted pots were transferred to an automatically controlled gas-tight growth chamber $(110 \mathrm{~cm}$ length, $250 \mathrm{~cm}$ width, $180 \mathrm{~cm}$ height $)$ and exposed to ${ }^{13} \mathrm{CO}_{2}$-fumigation for 18 days (14-31 May 2013), during the vegetative growth period (including the entire tillering stage). The growth chambers were placed in a rice field to ensure that the environmental conditions of the labelled and control plants would be identical for labelled plants and unlabelled controls. The remaining 30 pots (20 planted, 10 unplanted), which served as controls for measuring natural ${ }^{13} \mathrm{C}$ abundance, were placed $10-15 \mathrm{~m}$ from the growth chambers. The surface of each planted pot was covered with black plastic sheeting to prevent algal photosynthesis in the floodwater and to ensure that only the rice shoots were exposed to ${ }^{13} \mathrm{CO}_{2}$, whereas the unplanted pots were left uncovered, so that the soils were directly exposed to ${ }^{13} \mathrm{CO}_{2}$ and phototrophic soil microbes could assimilate atmospheric ${ }^{13} \mathrm{CO}_{2}$. All pots were watered every few days in order to maintain a water depth of $2-3 \mathrm{~cm}$ above the soil surface until harvest. Weeds were removed manually.

The $\mathrm{CO}_{2}$ concentrations of the growth chambers were measured using an infrared analyser (Shsen-QZD, Qingdao, China) and maintained at $360-380 \mu \mathrm{L}^{-1}$. The ${ }^{13} \mathrm{CO}_{2}$ was generated by acidifying $\mathrm{Na}_{2}^{13} \mathrm{CO}_{3}\left(1.0 \mathrm{M}, 99\right.$ atom $\%{ }^{13} \mathrm{C}$; Cambridge Isotope Laboratories, Tewksbury, MA, USA) with $\mathrm{H}_{2} \mathrm{SO}_{4}(0.5 \mathrm{M})$ in beakers that were placed inside the growth chambers. During the labelling period, ${ }^{13} \mathrm{CO}_{2}$ was only released when $\mathrm{CO}_{2}$ concentrations fell below $360 \mu \mathrm{L}^{-1}$, and at $\mathrm{CO}_{2}$ concentrations $>380 \mu \mathrm{L}^{-1}$, the gas flow was diverted and passed through $\mathrm{CO}_{2}$ traps ( $\mathrm{NaOH}$ solution). An air-conditioning system was used to control the temperature inside the chamber within $1{ }^{\circ} \mathrm{C}$ of the ambient temperature in the rice field. Two fans continuously circulated the air in the growth chamber.

\section{$2.3 \quad{ }^{13} \mathrm{C}$-labelled substrate collection}

All the rice plants and soils were sampled destructively after 18 days of ${ }^{13} \mathrm{CO}_{2}$ labelling. Rice shoots were removed at their bases, whereas rice roots were separated from the soil by washing with deionized water, and both shoots and roots were dried at $60^{\circ} \mathrm{C}$ for $48 \mathrm{~h}$, then cut into $<5 \mathrm{~mm}$ pieces. To collect ${ }^{13} \mathrm{C}$-labelled rhizodeposits, moist soil was removed from the rice roots by gentle shaking, and the soil adhering to the roots was collected by washing the roots with distilled water. Subsequently, the resulting soil slurries were mixed and centrifuged at $13000 \times g$ for $15 \mathrm{~min}$. The lowdensity fine roots were removed, along with the supernatants, whereas the rhizodeposits were collected with the soil. To obtain microbe-assimilated ${ }^{13} \mathrm{C}$, we collected soil from ${ }^{13} \mathrm{C}$ treated, unplanted pots and mixed it thoroughly.

\subsection{Soil incubation}

To determine the PEs of different $\mathrm{C}$ sources and the effect of different $\mathrm{C}$ substrates on $\mathrm{CO}_{2}$ and $\mathrm{CH}_{4}$ emission, we conducted a 300-day incubation study of paddy soils that had been supplemented with ${ }^{13} \mathrm{C}$-labelled shoots, roots, rhizodeposits, or microbe-assimilated C. Five treatments were used: (1) unlabelled and unplanted paddy soil supplemented with ${ }^{13} \mathrm{C}$-labelled shoot residue (shoot-C), (2) unlabelled and unplanted paddy soil supplemented with ${ }^{13} \mathrm{C}$-labelled root residue (root-C), (3) soil containing ${ }^{13} \mathrm{C}$-labelled rhizodeposits (rhizo-C), (4) ${ }^{13} \mathrm{C}$-labelled soil containing ${ }^{13} \mathrm{C}$ labelled microbe-assimilated $\mathrm{C}$ (micro-C), and (5) unlabelled and unplanted soil without supplementation (CK). Three additional treatments were used to determine the natural occurrence of ${ }^{13} \mathrm{C}$ : (1) unlabelled and unplanted paddy soil with unlabelled shoot residue, (2) unlabelled and unplanted paddy soil with unlabelled root residue, and (3) unlabelled and unplanted paddy soil with unlabelled rhizodeposits.

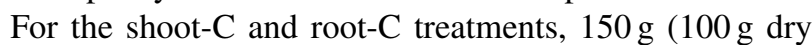
weight equivalent) unlabelled, unplanted soil with a water content of $50 \%$ was homogenized with $0.6 \mathrm{~g}$ of labelled and dried shoot and root residue, respectively, with a final residue content of $6 \mathrm{~g} \mathrm{~kg}^{-1}$. Subsequently, the samples were transferred to $500 \mathrm{~mL}$ serum bottles with $100 \mathrm{~mL}$ deionized water to ensure a water layer of $2-3 \mathrm{~cm}$, and the bottles were sealed with butyl rubber stoppers. For the rhizo-C and micro-C treatments, $150 \mathrm{~g}$ of fresh soil containing either ${ }^{13} \mathrm{C}$-labelled rhizodeposits (from rice roots) or ${ }^{13} \mathrm{C}$-labelled microbe-assimilated $\mathrm{C}$ (from labelled, unplanted pots) were directly weighed into $500 \mathrm{ml}$ serum bottles. Incubation was conducted at $25^{\circ} \mathrm{C}$ in the dark for 300 days, with four replicates for each treatment. $\mathrm{CH}_{4}$ and $\mathrm{CO}_{2}$ concentrations of the 
headspace samples were collected at 1, 3, 5, 10 days, then every 10 days after sealing, the gas was collected using a gas-tight syringe and stored in pre-evacuated Exetainer glass bottles (Labco, High Wycombe, UK). After each sampling point, the serum bottle was ventilated for $10 \mathrm{~min}$, then sealed with butyl rubber stoppers.

\subsection{Analytical methods}

The C content of the soil and plant residues (shoots and roots) was determined using dry combustion with an elemental analyser (vario MAX; Elementar Analysensysteme $\mathrm{GmbH}$, Hanau, Germany), whereas the $\mathrm{CH}_{4}$ and $\mathrm{CO}_{2}$ concentrations of the headspace samples were measured using a gas chromatographer (Agilent 7890A, Agilent Technologies, Alto Palo, California, USA) equipped with a thermal conductivity detector for measuring $\mathrm{CO}_{2}$ and a flame ionization detector for measuring $\mathrm{CH}_{4}$. In addition, the stable $\mathrm{C}$ isotope composition of soils and plant residues were analysed using an isotope ratio mass spectrometer coupled with an elemental analyser (FLASH 2000; Thermo Fisher Scientific, USA), whereas the stable $\mathrm{C}$ isotope composition of $\mathrm{CO}_{2}$ and $\mathrm{CH}_{4}$ in the headspace samples were analysed using the isotope ratio mass spectrometer coupled with a GasBench (Thermo Fisher Scientific, USA).

\subsection{Calculations and statistical analysis}

The $\delta^{13} \mathrm{C}$ values of plant residues, rhizodeposits, microbeassimilated $\mathrm{C}$, soils, $\mathrm{CO}_{2}$, and $\mathrm{CH}_{4}$ were converted in $\delta(\%)$ relative to the Pee Dee Belemnite (PDB, 0.0111802) standard and further expressed in atom $\%$ as the following:

atom $\%=\frac{100 \cdot 0.0111802 \cdot\left(\frac{\delta}{1000}+1\right)}{1+0.0111802 \cdot\left(\frac{\delta}{1000}+1\right)}$,

and the incorporation of ${ }^{13} \mathrm{C}\left({ }^{13} \mathrm{C}\right.$ excess $)$ in plant residues, rhizodeposits, microbe-assimilated $\mathrm{C}$, bulk soils, $\mathrm{CO}_{2}$, and $\mathrm{CH}_{4}$ was calculated as follows:

$$
\begin{aligned}
\text { excess }{ }^{13} \mathrm{C}_{\text {sample }} & =\left[\left(\text { atom } \%{ }^{13} \mathrm{C}\right)_{\mathrm{L}}\right. \\
& \left.-\left(\operatorname{atom} \%{ }^{13} \mathrm{C}\right)_{\mathrm{UL}}\right] \cdot \mathrm{C}_{\text {sample }} / 100,
\end{aligned}
$$

where $\left(\text { atom } \%{ }^{13} \mathrm{C}\right)_{\mathrm{L}}$ and $\left(\text { atom } \%{ }^{13} \mathrm{C}\right)_{\mathrm{UL}}$ are the atom $\%$ ${ }^{13} \mathrm{C}$ in labelled and unlabelled samples, respectively, and $\mathrm{C}_{\text {sample }}$ are the $\mathrm{C}$ contents of each sample.

The ${ }^{13} \mathrm{CO}_{2}$ and ${ }^{13} \mathrm{CH}_{4}$ efflux (\%) were calculated as the increases in excess of ${ }^{13} \mathrm{C}-\mathrm{CO}_{2}$ and ${ }^{13} \mathrm{C}-\mathrm{CH}_{4}$ within each sampling interval, respectively, as percentages of the ${ }^{13} \mathrm{C}$ input. The mineralization percentage of the input ${ }^{13} \mathrm{C}$ was calculated as the sum of total ${ }^{13} \mathrm{C}_{\text {in }} \mathrm{CO}_{2}$ and $\mathrm{CH}_{4}$ at each sampling day, relative to the initially added total ${ }^{13} \mathrm{C}$.

The kinetics of the mineralization were described by fitting a first-order single exponential function:

$y=a\left(1-e^{-b x}\right)$, where $a$ describes the amount of bioavailable labelled substrate pool, $b$ is the mineralization rate of substrate, and $x$ is time (day). Obtained parameters were used to calculate the mean residence time as $1 / b$ and half-life as $\ln (2) / b$.

The end-member mixing model was used to calculate the fractions of SOC- $\left(\mathrm{C}_{\mathrm{SOC}}\right)$ and plant-residue-derived $\mathrm{C}\left(\mathrm{C}_{\text {shoot }}\right.$ and $\mathrm{C}_{\text {root}}$ ), as described by Phillips et al. (2005) and Wild et al. (2014). This model allows the combination of mass spectrometric and efflux measurements. The shoot-derived ${ }^{13} \mathrm{CO}_{2}$ emission $\left({ }^{13} \mathrm{CO}_{2 \text { shoot-derived }}\right)$ was calculated as follows:

$$
\begin{aligned}
{ }^{13} \mathrm{CO}_{2 \text { shoot-derived }} & =\frac{\text { atom } \% \mathrm{CO}_{2 \text { shoot }}-\text { atom } \% \mathrm{CO}_{2 \mathrm{CK}}}{\text { atom } \% \mathrm{C}_{\text {shoot }}-\text { atom } \% \mathrm{C}_{\text {soil }}} \\
& \times \mathrm{CO}_{2 \text { shoot }-\mathrm{C}},
\end{aligned}
$$

where atom $\% \mathrm{CO}_{2 \text { shoot }}$ and atom $\% \mathrm{CO}_{2 \mathrm{CK}}$ are the atom $\%$ ${ }^{13} \mathrm{C}$ values of $\mathrm{CO}_{2}$ derived from shoot treated soil and untreated soil $(\mathrm{CK})$, respectively; atom $\% \mathrm{C}_{\text {shoot }}$ and atom $\% \mathrm{C}_{\text {soil }}$ are the atom $\%{ }^{13} \mathrm{C}$ values of shoot and bulk soil, respectively; and $\mathrm{CO}_{2 \text { shoot-C }}$ is the total $\mathrm{CO}_{2}$ derived from shoot treated soil; and the shoot-derived ${ }^{13} \mathrm{CH}_{4}$ emission $\left({ }^{13} \mathrm{CH}_{4 \text { shoot-derived }}\right)$ and the root-derived ${ }^{13} \mathrm{CO}_{2}$ and ${ }^{13} \mathrm{CH}_{4}$ emission $\left({ }^{13} \mathrm{CO}_{2 \text { root-derived and }}{ }^{13} \mathrm{CH}_{4 \text { root-derived }}\right.$, respectively) were calculated similarly (Phillips et al., 2005; Ye et al., 2015).

The $\mathrm{PE}$ of $\mathrm{SOM}$ on $\mathrm{CO}_{2}$ and $\mathrm{CH}_{4}$ emission was calculated as follows:

$\mathrm{PE}_{t}(\%)=\frac{\mathrm{Gas}-\mathrm{Gas}_{\mathrm{CK}}}{\operatorname{Gas}_{\mathrm{CK}}} \times 100$,

where $\mathrm{PE}_{t}$ is the $\mathrm{PE}$ at time $t$ (day), gas is the total amount of $\mathrm{CO}_{2}$ and $\mathrm{CH}_{4}$ derived from native $\mathrm{SOC}$ mineralization in the treatment of shoot- $\mathrm{C}$ and root- $\mathrm{C}, \mathrm{Gas}_{\mathrm{CK}}$ is the SOC mineralization in the CK treatment (Hu et al., 2012).

Analysis of variance in conjunction with Duncan's multiple range test $(p<0.05)$ and correlation analysis were conducted using SPSS 17 (SPSS Inc., Chicago, IL, USA), and figures were created using Origin 8.5 (OriginLab, Northampton, MA, USA).

\section{Results}

\section{1 $\mathrm{CO}_{2}$ and $\mathrm{CH}_{4}$ emission of carbon substrate-treated soils}

The excess ${ }^{13} \mathrm{C}$ per $100 \mathrm{~g}$ soil was $11.4,5.75,1.61$, and 0.49 $\mathrm{mg}$ in the shoot- $\mathrm{C}$, root- $\mathrm{C}$, rhizo- $\mathrm{C}$, and micro- $\mathrm{C}$ treatments, respectively (Table 1 ). The ${ }^{13} \mathrm{CO}_{2}$ efflux from the each treatment increased rapidly at the beginning of the incubation, peaked after 20 days, then decreased gradually (Fig. 1a). The $\mathrm{CO}_{2}$ efflux rates from the shoot-C- and root-C-treated soils were 0.71 and $0.66 \%$ of the initial ${ }^{13} \mathrm{C}$ per day, respectively, which was higher than those of rhizo-C- $(0.11 \%$ of initial ${ }^{13} \mathrm{C}$ per day) and micro-C-treated $\left(0.06 \%\right.$ of initial ${ }^{13} \mathrm{C}$ per day) soils. The ${ }^{13} \mathrm{CH}_{4}$ efflux rates exhibited similar patterns 
Table 1. Carbon (C) and atomic ${ }^{13} \mathrm{C}$ contents and amount of ${ }^{13} \mathrm{C}$ added to untreated bulk soil and soils treated with one of four labelled $\mathrm{C}$ substrates.

\begin{tabular}{lrrrrr}
\hline & Bulk soil & Shoot-C & Root-C & Rhizo-C & Micro-C \\
\hline C content $(\%)$ & $1.80 \pm 0.12$ & $40.50 \pm 2.13$ & $28.60 \pm 1.15$ & $1.89 \pm 0.12$ & $1.90 \pm 0.11$ \\
Atomic ${ }^{13} \mathrm{C}(\%)$ & $1.08 \pm 0.02$ & $5.78 \pm 0.09$ & $4.43 \pm 0.07$ & $1.16 \pm 0.03$ & $1.11 \pm 0.02$ \\
Total excess of ${ }^{13} \mathrm{C}(\mathrm{mg})$ & - & $11.43 \pm 0.52$ & $5.75 \pm 0.41$ & $1.61 \pm 0.06$ & $0.49 \pm 0.05$ \\
\hline
\end{tabular}

Bulk soil, unplanted control soil; shoot-C, paddy soil supplemented with ${ }^{13} \mathrm{C}$-labelled shoot residue; root-C, paddy soil supplemented with ${ }^{13} \mathrm{C}$-labelled root residue; rhizo-C, paddy soil supplemented with ${ }^{13} \mathrm{C}$-labelled rhizodeposits; micro-C, paddy soil supplemented with ${ }^{13} \mathrm{C}$-labelled microbe-accumulated $\mathrm{C}$.

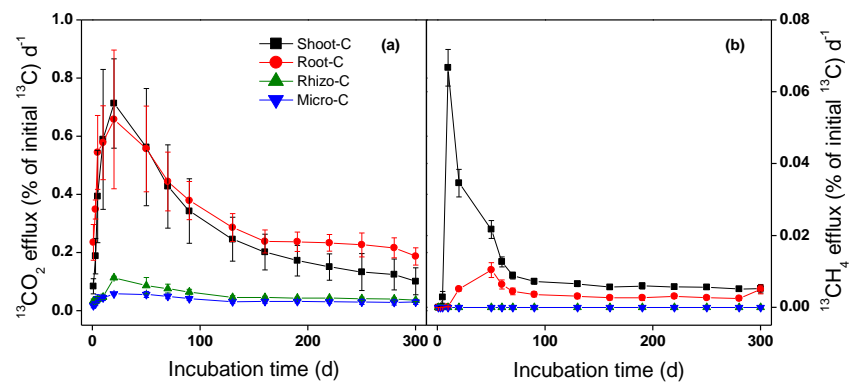

Figure 1. ${ }^{13} \mathrm{CO}_{2}$ (a) and ${ }^{13} \mathrm{CH}_{4}$ (b) efflux per day over the 300 day incubation period. Values and error bars represent mean $\%$ initial ${ }^{13} \mathrm{C} \pm \mathrm{SE}(n=4)$. Shoot-C, unlabelled paddy soil supplemented with ${ }^{13} \mathrm{C}$-labelled shoot residue; root-C, unlabelled paddy soil supplemented with ${ }^{13} \mathrm{C}$-labelled root residue; rhizo-C, paddy soil containing ${ }^{13} \mathrm{C}$-labelled rhizodeposits; micro-C, paddy soil containing ${ }^{13} \mathrm{C}$-labelled microbe-accumulated $\mathrm{C}$.

(Fig. 1b). The cumulative ${ }^{13} \mathrm{CO}_{2}$ and ${ }^{13} \mathrm{CH}_{4}$ emissions increased exponentially during the first 60 days of incubation, after which they increased more slowly (Fig. 2). The total ${ }^{13} \mathrm{CO}_{2}$ emissions accounted for 28.6 and $43.8 \%$ of the initial ${ }^{13} \mathrm{C}$ from shoot-C and root-C, respectively, and 7.90 and $7.70 \%$ of the initial ${ }^{13} \mathrm{C}$ from rhizo-C and micro-C (Fig. 2a). The cumulative ${ }^{13} \mathrm{CH}_{4}$ emissions only accounted for 3.3 and $1.6 \%$ of the initial ${ }^{13} \mathrm{C}$ from shoot- $\mathrm{C}$ and root- $\mathrm{C}$, respectively, whereas no ${ }^{13} \mathrm{CH}_{4}$ was detected in the emission of the rhizo-C- and micro-C-treated soils (Fig. 2b).

The cumulative mineralization of substrate-derived ${ }^{13} \mathrm{C}$ was more rapid at the beginning of the incubation and followed a single exponential model (Fig. S1 in the Supplement), and at the end of the incubation, we found that the percentage of substrate-derived $\mathrm{C}$ that was mineralized was highest in root-C-treated soils $(45.4 \%)$, followed by shootC- $(31.9 \%)$, rhizo-C- $(7.90 \%)$, and micro-C-treated $(7.70 \%)$ soils. About 0.3 and $0.1 \%$ of the cumulative $\mathrm{C}$ emissions were derived from labelled rhizo-C and micro-C. In addition, the size of the bioavailable labelled substrate $\mathrm{C}$ pool in the shoot-C- and root-C-treated soils was 34.2 and $46.2 \%$, respectively, which was 4 - to 5-fold larger than that of the micro-C- $(9.7 \%)$ and rhizo-C-treated $(7.8 \%)$ soils, and the mean residence times (MRT) of the shoot-C-, root-C-, rhizo-
Table 2. Bioavailable labelled substrate $\mathrm{C}$ pool, mean residence time (MRT), and half-life of cumulative ${ }^{13} \mathrm{C}$ recovery in $\mathrm{CO}_{2}$ and $\mathrm{CH}_{4}$ of soils incubated with one of four labelled $\mathrm{C}$ substrates.

\begin{tabular}{lrrrr}
\hline Treatment & Size $(\%)$ & MRT $(\mathrm{d})$ & Half-life $(\mathrm{d})$ & $R^{2}$ \\
\hline Shoot-C & $32.4 \pm 0.56$ & $39.5 \pm 0.63$ & $27.4 \pm 0.55$ & 0.99 \\
Root-C & $44.9 \pm 1.12$ & $50.3 \pm 0.71$ & $34.7 \pm 0.62$ & 0.99 \\
Rhizo-C & $7.3 \pm 0.38$ & $66.2 \pm 0.92$ & $46.4 \pm 1.31$ & 0.98 \\
Micro-C & $9.1 \pm 0.44$ & $195 \pm 1.52$ & $136 \pm 1.66$ & 0.98 \\
\hline
\end{tabular}

The size of bioavailable labelled substrate $\mathrm{C}$ pool $\left(\%\right.$ initial $\left.{ }^{13} \mathrm{C}\right)$, MRT, and $R^{2}$ were calculated based on Fig. S1. Shoot-C, paddy soil supplemented with ${ }^{13} \mathrm{C}$-labelled shoot residue; root-C, paddy soil supplemented with ${ }^{13} \mathrm{C}$-labelled root residue; rhizo-C, paddy soil supplemented with ${ }^{13} \mathrm{C}$-labelled rhizodeposits; micro-C, paddy soil supplemented with ${ }^{13} \mathrm{C}$-labelled microbe-accumulated C.

C-, and micro-C-treated soils were 39.5, 50.3, 66.2, and 195 days, respectively (Table 2).

\subsection{Priming effect of shoot- $\mathrm{C}$ and root- $\mathrm{C}$ on $\mathrm{CO}_{2}$ and $\mathrm{CH}_{4}$ emission}

During incubation, the emission rates of $\mathrm{CO}_{2}$ and $\mathrm{CH}_{4}$ from control soils ranged from 4.7 to $15.9 \mathrm{mg} \mathrm{kg}^{-1} \mathrm{~d}^{-1}$. The addition of shoot- $\mathrm{C}$ and root- $\mathrm{C}$ increased total $\mathrm{C}$ emissions from native SOC up to 11.4 and 2.3 times than that of the untreated soils by day 20, respectively, and the PE persisted to the end of incubation period. The $\mathrm{C}$ emission from native SOC increased linearly during the first 20 days, then decreased rapidly (Fig. 3). Furthermore, the PE of shoot-C peaked at $378 \%$ after 20 days of incubation and decreased to $52 \%$ by the end of the incubation, whereas the PE of root-C peaked at $43 \%$ after 50 days of incubation, then decreased to $2.9 \%$. Thus, the positive PE of shoot-C was clearly stronger than that of root-C, especially since the PE of root-C was insignificant (Fig. 4).

\subsection{Mineralization of soil organic carbon in rhizo-C- and micro-C-treated soils}

The total $\mathrm{C}$ emissions of rhizo-C- and micro-C-treated-soils increased significantly from 116 and $81 \mathrm{mg} \mathrm{kg}^{-1}$ after 10 days of incubation to 1754 and $1785 \mathrm{mg} \mathrm{kg}^{-1}$ by the end of the incubation, respectively. The total $\mathrm{C}$ emission of rhizo-C- 

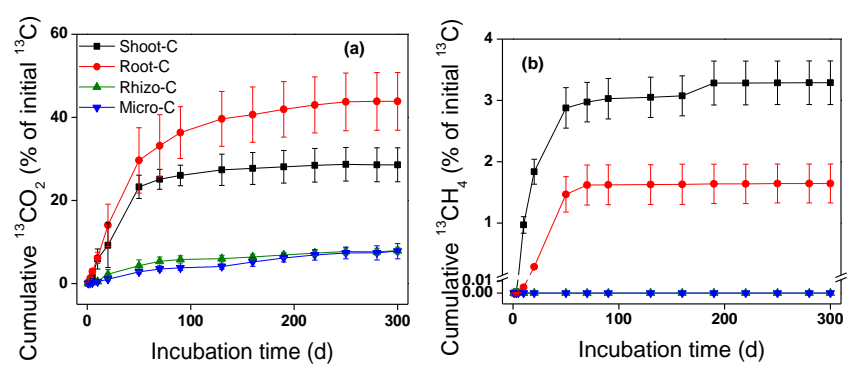

Figure 2. Cumulative ${ }^{13} \mathrm{CO}_{2}$ (a) and ${ }^{13} \mathrm{CH}_{4}$ (b) emissions over the 300-day incubation period. Values and error bars represent mean $\%$ of initial ${ }^{13} \mathrm{C} \pm \mathrm{SE}(n=4)$. Shoot-C, unlabelled paddy soil supplemented with ${ }^{13} \mathrm{C}$-labelled shoot residue; root-C, unlabelled paddy soil supplemented with ${ }^{13} \mathrm{C}$-labelled root residue; rhizo-C, paddy soil containing ${ }^{13} \mathrm{C}$-labelled rhizodeposits; micro-C, paddy soil containing ${ }^{13} \mathrm{C}$-labelled microbe-accumulated $\mathrm{C}$.

treated soil was significantly higher than that of the micro-Ctreated and untreated soil during the first 200 days of incubation; however, no significant differences were identified at the end of the incubation (Fig. 5a). In addition, the total ${ }^{13} \mathrm{C}$ emissions derived from the labelled substrates was significantly higher for the rhizo-C-treated soils than for the microC-treated soils ( $p<0.05$; Fig. 5 b). However, the cumulative $\mathrm{C}$ mineralization of neither the rhizo-C- nor the micro-Ctreated soils was significantly different from that of untreated soils, which suggested that the rhizodeposits and microbeassimilated $\mathrm{C}$ had no positive effect on the mineralization of native SOC.

\section{Discussion}

\subsection{Mineralization of carbon substrates in paddy soil}

The effluxes of both $\mathrm{CO}_{2}$ and $\mathrm{CH}_{4}$ from soils treated with ${ }^{13} \mathrm{C}$-labelled substrates exhibited a rapid increase at the beginning of the incubation, followed by a slow decrease (Fig. 1), which indicated that microbes prefer fresh $\mathrm{C}$ substrates over native SOC (Yuan et al., 2014), as has been reported by previous studies on the decomposition of fresh $\mathrm{C}$ substrates in both paddy and upland soils (Lu et al., 2003; Parshotam et al., 2000). In these systems, the initial rapid decomposition is due to the addition of easily degradable organic $\mathrm{C}$ in the added substrates, such as starch and other labile compounds. Then, after the exhaustion of labile $\mathrm{C}$ from the added substrates, more recalcitrant components, such as cutin and lignin, from both the added substrates and native SOM, are utilized along with native mineral-stabilized SOC (Baumann et al., 2009). The transition could also involve an alteration in species dominance, with rapidly proliferating bacteria using more available compounds during the early stages of decomposition and slower-growing fungi using the
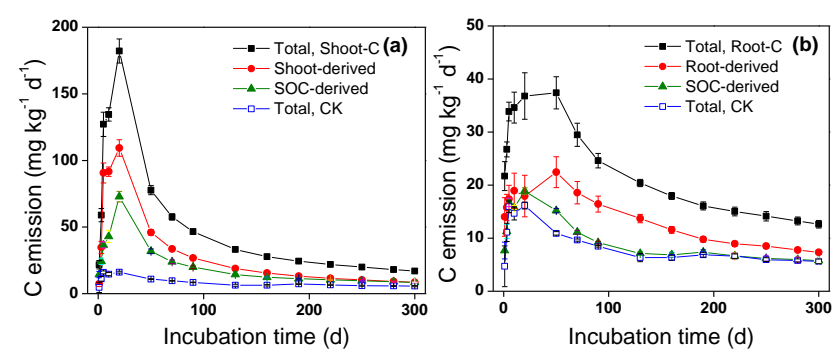

Figure 3. Rates of $\mathrm{CO}_{2}-\mathrm{C}$ and $\mathrm{CH}_{4}-\mathrm{C}$ emissions from shoot-C(a) and root-C-treated (b) soils over the 300-day incubation period. Values and error bars represent means $\pm \operatorname{SE}(n=4)$. Shoot-C, ${ }^{13} \mathrm{C}$ labelled shoot residue; root-C, ${ }^{13} \mathrm{C}$-labelled root residue; $\mathrm{SOC}$, soil organic carbon; CK, unlabelled and unplanted soil without supplementation.

more recalcitrant components during later stages (Baumann et al., 2009; Brant et al., 2006).

Both $\mathrm{CO}_{2}$ and $\mathrm{CH}_{4}$ efflux are important components of the $\mathrm{C}$ cycle in paddy soils and represent a major proportion of the $\mathrm{C}$ released by microbial decomposition (Yuan et al., 2014), and the results of the present study suggest that the mineralization of shoot- and root-derived ${ }^{13} \mathrm{C}$ was $\sim 3-4$ times higher than that of rhizodeposit- and microbe-derived ${ }^{13} \mathrm{C}$ (i.e. root-C $>$ shoot-C $>$ rhizo-C $>$ micro-C; Fig. 2 ). The present study also found that the percentage of root-derived ${ }^{13} \mathrm{C}$ recovered as $\mathrm{CO}_{2}$ was 1 .6-fold higher than that of shootderived ${ }^{13} \mathrm{C}$ recovered as $\mathrm{CO}_{2}$. This suggests that root residue was more easily decomposed, a conclusion that was also supported by the higher ${ }^{13} \mathrm{CO}_{2}$ efflux of root-C-treated soils.

However, the $\mathrm{C}$ mineralization rates of rhizo-C- and micro-C-treated soils were much slower, and the MRTs of rhizo-C- and micro-C-treated soils were 2- to 4-fold higher than those of shoot-C- and root-C-treated soils. Presumably, this resulted from the formation of mineral-associated organic matter during the labelling period, which was well protected from microbial degradation and had a slow turnover rate (Basler et al., 2015; Mikutta et al., 2014; Saidy et al., 2012; Schurig et al., 2013). Another possible reason for this observation is that most of the $\mathrm{C}$ in rhizo-C- and micro$\mathrm{C}$-treated soils was not mineralized to $\mathrm{CO}_{2}$ but instead underwent intensive internal recycling (Gunina and Kuzyakov, 2015; Knowles et al., 2010). In addition, the easily available substrate-derived $\mathrm{C}$ could be incorporated into metabolic products, such as sugars, carboxylic acids, and amino acids, which in turn are used to build up stable cell membranes, cell walls, or polymers (Apostel et al., 2015; Gunina et al., 2014). Microorganisms are also associated with minerals, thus are involved in the formation of occluded particulate organic matter and mineral-associated organic matter (Basler et al., 2015, Schurig et al., 2013), the latter of which is considered especially stable. 


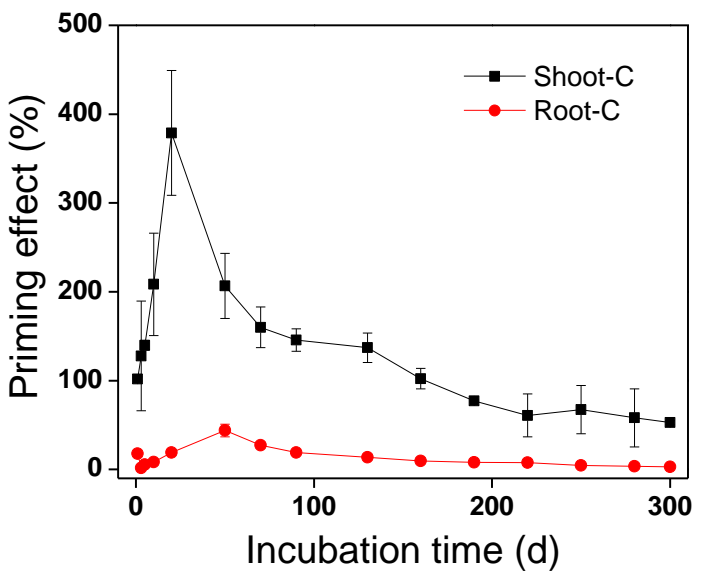

Figure 4. Priming effect of ${ }^{13} \mathrm{C}$-labelled plant residues over the 300-day incubation period. Values and error bars represent means \pm SE $(n=4)$. Shoot-C, unlabelled paddy soil supplemented with ${ }^{13} \mathrm{C}$-labelled shoot residue; root-C, unlabelled paddy soil supplemented with ${ }^{13} \mathrm{C}$-labelled root residue.

\subsection{Effect of carbon substrates on native SOC mineralization}

In the present study, the emission of $\mathrm{CO}_{2}$ and $\mathrm{CH}_{4}$ by shoot$\mathrm{C}$ - and root-C-treated soils during the first 50 days were mainly derived from plant residue $\mathrm{C}$, after which the relative contribution of native SOC increased. For shoot-C, a positive PE was observed over the entire incubation period, whereas for root-C it was only significant during the early stages of the incubation (Fig. 4). These results support previous reports that the initial phase of rapid decomposition results from the addition of easily degraded organic $\mathrm{C}$ and other available nutrients with the residues that promote both microbial activity and SOC decomposition (Chen et al., 2014). The compounds which decomposed during the slower phase were less available for microbial growth, and as a result of $\mathrm{C}$ limitation, most of the available $\mathrm{C}$ was likely incorporated into cells and converted to storage compounds, rather than used for growth or respiration (Lu et al., 2003; Brant et al., 2006). However, the extracellular enzymes generated to degrade recalcitrant $\mathrm{C}$ substrates might be more effective in decomposing SOC at later stages of incubation, leading to a positive PE (Chen et al., 2014). In addition, the two phases of exogenous $C$ decomposition and the mechanisms of PE simultaneously influence the strength and extent of native SOC mineralization (Chen et al., 2014; Ye et al., 2015).

Both rhizo-C and micro-C augmented the $\mathrm{C}$ content of paddy soil (1.89 and $1.90 \%$, respectively) over that of the untreated soil (1.81\%), although the C emissions of rhizo-Cand micro-C-treated soils were similar to those of untreated soil. Since approximately 0.3 and $0.1 \%$ of the substrate C were mineralized, it suggests that rhizodeposits and microbeassimilated $\mathrm{C}$ input failed to stimulate the mineralization of native SOC and, instead, resulted in negative priming. There-
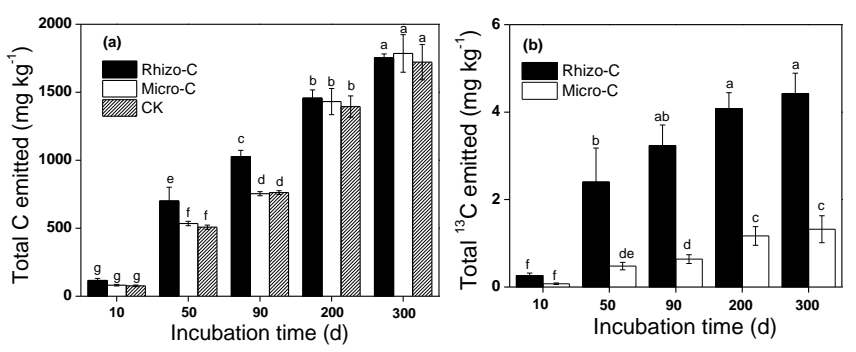

Figure 5. Total $\mathrm{C}$ (a) and ${ }^{13} \mathrm{C}$ (b) emission by ${ }^{13} \mathrm{C}$-labelled rhizo$\mathrm{C}$ - and micro-C-accumulated C-treated soils over the 300-day incubation period. Values and error bars represent means $\pm \operatorname{SE}(n=4)$. Different letters indicate significant differences at $p<0.05$ (Duncan multiple range test). Rhizo-C, paddy soil containing ${ }^{13} \mathrm{C}$ labelled rhizodeposits; micro-C, paddy soil containing ${ }^{13} \mathrm{C}$-labelled microbe-accumulated $\mathrm{C}$; CK, unlabelled and unplanted soil without supplementation.

fore, it seems that rhizo-C and micro-C protect native SOC and increase the organic $\mathrm{C}$ storage of paddy soil (Ge et al., 2012; Li and Yagi, 2004; Gunina et al., 2015). In addition, the lower $\mathrm{C}$ contents of rhizo- $\mathrm{C}$ and micro-C compared to shoot$\mathrm{C}$ and root-C may reflect the different behaviours of the organic $\mathrm{C}$ substrates in the soil. Roots and shoots, for example, enter the soil as particulate and unprotected organic matter, which is highly available for microorganism uptake and assimilation (i.e. 31.9 and $45.4 \%$, respectively), and were mineralized within the 300-day incubation period (Fig. S1). Meanwhile, rhizodeposits consist mostly of low molecular weight sugars and acids that are highly bioavailable ( $\mathrm{Lu}$ et al., 2002), and the relatively long MRTs of rhizo-C (Table 2) suggests that the $\mathrm{C}$ was stabilized during the incubation, either by adsorption or by microbial metabolism and recycling (Lu et al., 2002; Gunina et al., 2014; Schurig et al., 2013). Micro-C also exhibited long MRTs in the incubation experiment (Table 2), which coincided with the observation that microbial residues accumulated in the soil (Schurig et al., 2013).

\section{Conclusions}

In the present study, root-C-treated soils exhibited the highest rate of $\mathrm{C}$ mineralization, followed by shoot-C-, rhizo-C-, and micro-C-treated soils, whereas the opposite trend was observed for MRT. By the end of the 300-day incubation, shootC-treated soils exhibited higher total mineralization and positive PEs, whereas root-C failed to exhibit a significant priming effect. Although plant residues are widely used for improving soil fertility, their contribution to SOC assimilation is inefficient, and their use also contributes to the emission of greenhouse gases. However, the present study demonstrates that both rhizodeposits and microbe-assimilated $\mathrm{C}$ can reduce native SOC decomposition and may more effectively contribute to the stability and sequestration of soil C. 


\section{The Supplement related to this article is available online at doi:10.5194/bg-13-4481-2016-supplement.}

Acknowledgements. The present study was supported by the National Natural Science Foundation of China (41430860, 41371304), the Strategic Priority Research Program of the Chinese Academy of Sciences (XDB15020401), the Open Foundation of Key Laboratory of Agro-ecological Processes in Subtropical Region, the Chinese Academy of Sciences Institute of Subtropical Agriculture (ISA2015101), and the Recruitment Program of High-End Foreign Experts of the State Administration of Foreign Experts Affairs, awarded to Georg Guggenberger (GDT20154300073). We thank the Public Service Technology Center, Institute of Subtropical Agriculture, Chinese Academy of Sciences for technical assistance. We are highly indebted to Kazayuki Inubushi and four other reviewers for their valuable comments on previous versions of the manuscript.

Edited by: Y. Kuzyakov

Reviewed by: three anonymous referees

\section{References}

Apostel, C., Dippold, M., and Kuzyakov, Y.: Biochemistry of hexose and pentose transformations in soil analyzed by positionspecific labeling and ${ }^{13}$ C-PLFA, Soil Biol. Biochem., 80, 199 208, 2015.

Basler, A., Dippold, M., Helfrich, M., and Dyckmans, J.: Microbial carbon recycling: an underestimated process controlling soil carbon dynamics - Part 2: $\mathrm{A} \mathrm{C}_{3}-\mathrm{C}_{4}$ vegetation change field labelling experiment, Biogeosciences, 12, 6291-6299, doi:10.5194/bg-126291-2015, 2015.

Bastida, F., Torres, I. F., Hernández, T., Bombach, P., Richnow, H. H., and García, C.: Can the labile carbon contribute to carbon immobilization in semiarid soils? Priming effects and microbial community dynamics, Soil Biol. Biochem., 57, 892-902, 2013.

Baumann, K., Marschner, P., Smernik, R. J., and Baldock, J. A.: Residue chemistry and microbial community structure during decomposition of eucalypt, wheat and vetch residues, Soil Biol. Biochem., 41, 1966-1975, 2009.

Blagodatsky, S., Blagodatskaya, E., Yuyukina, T., and Kuzyakov, Y.: Model of apparent and real priming effects: Linking microbial activity with soil organic matter decomposition, Soil Biol. Biochem., 42, 1275-1283, 2010.

Brant, J. B., Sulzman, E. W., and Myrold, D. D.: Microbial community utilization of added carbon substrates in response to longterm carbon input manipulation, Soil Biol. Biochem., 38, 22192232, 2006.

Chen, R., Senbayram, M., Blagodatsky, S., Myachina, O., Dittert, K., Lin, X., Blagodatskaya, E., and Kuzyakov, Y.: Soil C and $\mathrm{N}$ availability determine the priming effect: microbial $\mathrm{N}$ mining and stoichiometric decomposition theories, Glob. Change Biol., 20, 2356-2367, 2014.

Conrad, R., Klose, M., Yuan, Q., Lu, Y., and Chidthaisong, A.: Stable carbon isotope fractionation, carbon flux partitioning and priming effects in anoxic soils during methanogenic degradation of straw and soil organic matter, Soil Biol. Biochem., 49, 193199, 2012.

Creamer, C. A., de Menezes, A. B., Krull, E. S., Sanderman, J., Newton-Walters, R., and Farrell, M.: Microbial community structure mediates response of soil $\mathrm{C}$ decomposition to litter addition and warming, Soil Biol. Biochem., 80, 175-188, 2015.

Ge, T. D., Yuan, H. Z., Zhu, H. H., Wu, X. H., Nie, S. A., Liu, C., Tong, C. L., Wu, J. S., and Brookes, P.: Biological carbon assimilation and dynamics in a flooded rice - Soil system, Soil Biol. Biochem., 48, 39-46, 2012.

Ge, T. D., Wu, X. H., Chen, X. J., Yuan, H. Z., Zou, Z., Li, B. Z., Zhou, P., Liu, S. L., Tong, C. L., Brookes, P., and Wu, J. S.: Microbial phototrophic fixation of atmospheric $\mathrm{CO}_{2}$ in China subtropical upland and paddy soils, Geochim. Cosmochim. Ac., 113, 70-78, 2013.

Glanville, H., Rousk, J., Golyshin, P., and Jones, D. L.: Mineralization of low molecular weight carbon substrates in soil solution under laboratory and field conditions, Soil Biol. Biochem., 48, 88-95, 2012.

Gunina, A. and Kuzyakov, Y.: Sugars in soil and sweets for microorganisms: Review of origin, content, composition and fate, Soil Biol. Biochem., 90, 87-100, 2015.

Gunina, A., Dippold, M. A., Glaser, B., and Kuzyakov, Y.: Fate of low molecular weight organic substrates in an arable soil: From microbial uptake to utilisation and stabilisation, Soil Biol Biochem., 77, 304-313, 2014.

Hooker, B., Morris, T., Peters, R., and Cardon, Z.: Long-term effects of tillage and corn stalk return on soil carbon dynamics, Soil Sci. Soc. Am. J., 69, 188-196, 2005.

Hu, L. L., Su, Y. R., He, X. Y., Wu, J. S., Zheng, H., Li, Y., and Wang, A.: Response of soil organic carbon mineralization in typical Karst soils following the addition of ${ }^{14} \mathrm{C}$-labeled rice straw and $\mathrm{CaCO}_{3}$, J. Sci. Food Agr., 92, 1112-1118, 2012.

Huo, L. J., Ji, X. H., Wu, J. M., Peng, H., and Zhu, J.: Effects of applications of exogenous organic carbon on methane emissions and oxidizable organic carbon in paddy soil, Res. Agric. Modern., 34, 496-501, 2013 (in Chinese with English abstract).

Jones, D. L. and Edwards, A. C.: Influence of sorption on the biological utilization of two simple carbon substrates, Soil Biol Biochem., 30, 1895-1902, 1998.

Johnson, J. M. F., Allmaras, R. R., and Reicosky, D. C.: Estimating substrate carbon from crop residues, roots and rhizodeposits using the national grain-yield database, Agron. J., 98, 622-636, 2006.

Kisselle, K. W., Garrett, C. J., Fu, S., Hendrix, P. F., Crossley Jr, D. A., Coleman, D. C., and Potter, R. L.: Budgets for root-derived $\mathrm{C}$ and litter-derived $\mathrm{C}$ : comparison between conventional tillage and no tillage soils, Soil Biol. Biochem., 33, 1067-1075, 2001.

Knowles, T. D. J., Chadwick, D. R., Bol, R., and Evershed, R. P.: Tracing the rate and extent of $\mathrm{N}$ and $\mathrm{C}$ flow from ${ }^{13} \mathrm{C},{ }^{15} \mathrm{~N}$ glycine and glutamate into individual de novo synthesized soil amino acids, Org. Geochem., 41, 1259-1268, 2010.

Kuzyakov, Y.: Priming effects: Interactions between living and dead organic matter, Soil Biol. Biochem., 42, 1363-1371, 2010.

Kuzyakov, Y. and Bol, R.: Substrates and mechanisms of priming effect induced in two grassland soils amended with slurry and sugar, Soil Biol. Biochem., 38, 747-758, 2006. 
Kuzyakov, Y., Friedel, J. K., and Stahr, K.: Review of mechanisms and quantification of priming effects, Soil Biol. Biochem., 32, 1485-1498, 2000.

Kuzyakov, Y., Siniakina, S. V., Ruehlmann, J., Domanski, G., and Stahr, K.: Effect of nitrogen fertilisation on below-ground carbon allocation in lettuce, J. Sci. Food Agr., 82, 1432-1441, 2002.

Kuzyakov, Y., Leinweber, P., Sapronov, D., and Eckhardt, K. U.: Qualitative assessment of rhizodeposits in non-sterile soil by analytical pyrolysis, J. Plant Nutr. Soil Sci., 166, 719-723, 2003.

Lal, R.: Soil Carbon Sequestration Impacts on Global Climate Change and Food Security, Science, 304, 1623-1627, 2004.

Li, Z. and Yagi, K.: Rice root-derived carbon input and its effect on decomposition of old soil carbon pool under elevated $\mathrm{CO}_{2}$, Soil Biol. Biochem., 36, 1967-1973, 2004.

Lu, Y. H., Watanabe, A., and Kimura, M.: Contribution of plantderived carbon to soil microbial biomass dynamics in a paddy rice microcosm, Biol. Fertil. Soil., 36, 136-142, 2002.

Lu, Y. H., Watanabe, A., and Kimura, M.: Carbon dynamics of rhizodeposits, root- and shoot-residues in a rice soil, Soil Biol. Biochem., 35, 1223-1230, 2003.

Mikutta, R., Lorenz, D., Guggenberger, G., Haumaier, L., and Freund, A.: Properties and reactivity of Fe-organic matter associations formed by coprecipitation versus adsorption: Clues from arsenate batch adsorption, Geochim. Cosmochim. Ac., 144, 258276, 2014

Molina, J. A. E., Clapp, C. E., Linden, D. R., Allmaras, R. R., Layese, M. F., Dowdy, R. H., and Cheng, H. H.: Modeling the incorporation of corn (Zea mays L.) carbon from roots and rhizodeposition into soil organic matter, Soil Biol. Biochem., 33, 83-92, 2001.

Nguyen, C.: Rhizodeposition of organic $\mathrm{C}$ by plants: mechanisms and controls, Agron., 23, 375-396, 2003.

Parshotam, A., Saggar, S., Searle, P. L., Daly, B. K., Sparling, G. P., and Parfitt, R. L.: Carbon residence times obtained from labeled ryegrass decomposition in soils under contrasting environmental conditions, Soil Biol. Biochem., 32, 75-83, 2000.

Phillips, D., Newsome, S. D., and Gregg, J.: Combining substrates in stable isotope mixing models: alternative methods, Oecologia, 144, 520-527, 2005.

Qiao, N., Schaefer, D., Blagodatskaya, E., Zou, X., Xu, X., and Kuzyakov, Y.: Labile carbon retention compensates for $\mathrm{CO}_{2}$ released by priming in forest soils, Glob. Change Biol., 20, 19431954, 2014.

Saidy, A. R., Smernik, R. J., Baldock, J. A., Kaiser, K., Sanderman, J., and Macdonald, L. M.: Effects of clay mineralogy and hydrous iron oxides on labile organic carbon stabilisation, Geoderma, 173, 104-110, 2012.
Schurig, C., Smittenberg, R. H., Berger, J., Kraft, F., Woche, S. K., Goebel, M. O., Heipieper, H. J., Miltner, A., and Kaestner, M.: Microbial cell-envelope fragments and the formation of soil organic matter: a case study from a glacier fore field, Biogeochemistry, 113, 595-612, 2013.

Sodano, M., Said-Pullicino, D., Fiori, A. F., Catoni, M., Martin, M., and Celi, L.: Sorption of paddy soil-derived dissolved organic matter on hydrous iron oxide-vermiculite mineral phases, Geoderma, 261, 169-177, 2016.

Wang, W., Lai, D. Y. F., Wang, C., Pan, T., and Zeng, C.: Effects of rice straw incorporation on active soil organic carbon pools in a subtropical paddy field, Soil Till. Res., 152, 8-16, 2015.

Weintraub, M., Scott-Denton, L., Schmidt, S., and Monson, R.: The effects of tree rhizodeposition on soil exoenzyme activity, dissolved organic carbon, and nutrient availability in a subalpine forest ecosystem, Oecologia, 154, 327-338, 2007.

Wild, B., Schnecker, J., Alves, R. J. E., Barsukov, P., Bárta, J., Čapek, P., Gentsch, N., Gittel, A., Guggenberger, G., Lashchinskiy, N., Mikutta, R., Rusalimova, O., Šantrůčková, H., Shibistova, O., Urich, T., Watzka, M., Zrazhevskaya, G., and Richter A.: Input of easily available organic $\mathrm{C}$ and $\mathrm{N}$ stimulates microbial decomposition of soil organic matter in arctic permafrost soil, Soil Biol. Biochem., 75, 143-151, 2014.

Ye, R., Doane, T. A., Morris, J., and Horwath, W. R.: The effect of rice straw on the priming of soil organic matter and methane production in peat soils, Soil Biol. Biochem., 81, 98-107, 2015.

Yuan, H. Z., Ge, T. D., Chen, C., O’Donnell, A. G., and Wu, J. S.: Significant role for microbial autotrophy in the sequestration of soil carbon, Appl. Environ. Microbiol., 78, 2328-2336, 2012a.

Yuan, H. Z., Ge, T. D., Wu, X., Liu, S., Tong, C. L., Qin, H., Wu, M., Wei, W. X., and Wu, J. S.: Long-term field fertilization alters the diversity of autotrophic bacteria based on the ribulose-1,5-biphosphate carboxylase/oxygenase (RubisCO) large-subunit genes in paddy soil, Appl. Microbiol. Biotechnol., 95, 1061-1071, 2012b.

Yuan, Q., Pump, J., and Conrad, R.: Straw application in paddy soil enhances methane production also from other carbon sources, Biogeosciences, 11, 237-246, doi:10.5194/bg-11-2372014, 2014.

Zhang, G., Yu, H., Fan, X., Liu, G., Ma, J., and Xu, H.: Effect of rice straw application on stable carbon isotopes, methanogenic pathway, and fraction of $\mathrm{CH}_{4}$ oxidized in a continuously flooded rice field in winter season, Soil Biol. Biochem., 84, 75-82, 2015. 